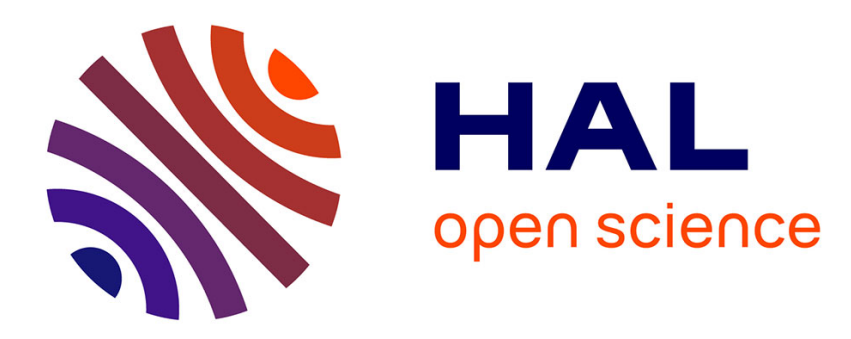

\title{
UV-visible absorption spectra of metallic clusters from TDDFT calculations
}

\author{
Franck Rabilloud
}

\section{To cite this version:}

Franck Rabilloud. UV-visible absorption spectra of metallic clusters from TDDFT calculations. The European Physical Journal D: Atomic, molecular, optical and plasma physics, 2013, 67 (1), pp.18. 10.1140/epjd/e2012-30448-x . hal-03233571

\section{HAL Id: hal-03233571 https://hal.science/hal-03233571}

Submitted on 13 Jan 2022

HAL is a multi-disciplinary open access archive for the deposit and dissemination of scientific research documents, whether they are published or not. The documents may come from teaching and research institutions in France or abroad, or from public or private research centers.
L'archive ouverte pluridisciplinaire HAL, est destinée au dépôt et à la diffusion de documents scientifiques de niveau recherche, publiés ou non, émanant des établissements d'enseignement et de recherche français ou étrangers, des laboratoires publics ou privés. 


\title{
UV-visible absorption spectra of metallic clusters from TDDFT calculations ${ }^{\star}$
}

\author{
Franck Rabilloud ${ }^{\mathrm{a}}$ \\ Institut Lumière Matière, UMR 5306 Université Lyon 1-CNRS, Université de Lyon, 69622 Villeurbanne Cedex, France
}

Received 18 July 2012 / Received in final form 20 November 2012

Published online 5 February 2013 - (C) EDP Sciences, Società Italiana di Fisica, Springer-Verlag 2013

\begin{abstract}
Absorption spectra of both pure silver or nickel clusters $\left(\mathrm{Ag}_{n}, n=6-55, \mathrm{Ni}_{p}, p=8-12\right)$ and mixed silver-nickel clusters $\left(\mathrm{Ag}_{n} \mathrm{Ni}_{n}, n=3-6\right)$ are investigated in the framework of the time-dependent density functional theory (TDDFT) with the use of the functional CAM-B3LYP. The spectra of silver nickel clusters are compared to those of pure silver and nickel clusters. An interpretation of spectroscopic patterns in terms of contribution from $s$ - and $d$-type excitations is presented. In particular the $d$ electrons of nickel atoms are found to play a crucial role in the optical transitions in Ni-rich systems.
\end{abstract}

\section{Introduction}

The physics of nanoscaled systems have attracted much interest in terms of both experiments and computations because of their application outlooks which appear to be more and more promising. In particular, the metal nanoparticles have been the object of a lot of attention due to their unique optical, electronic and catalytic properties [1]. Large efforts have been engaged in the synthesis methods of metal nanoparticles in order to control the size, stability, shape and the atomic arrangement, on which depend their physical and chemical properties. Noble metal clusters were extensively investigated, particularly for their striking optical transitions [2-4] and for their strong fluorescence emissions [5]. Numerous bimetallic clusters containing metal noble atoms and/or transition metal atoms have also been studied both in experiments and simulations since the properties of nanoparticles can also be tailored by mixing several elements together $[2,6,7]$.

Experimentally, the optical spectra of small silver cationic $\operatorname{Ag}_{n}^{+}(n=9,11,15,21,50,70)$ clusters or neutral $\operatorname{Ag}_{n}(n=2-39)$ clusters were first measured in the early years of nineties [8-11]. Then further studies were performed with various experimental setup and at various temperature $[4,12,13]$. For very small $\mathrm{Ag}_{n}$ clusters $(n \leq 8)$, the absorption spectra are characterized by a strong response on the $3-5 \mathrm{eV}$ range with several narrow or broad peaks, while for $n \geq 12$ they are characterized by the emergence of a dominant and relatively broad peak between 3 and $4 \mathrm{eV}$. At the nanometric scale (i.e. $2-10 \mathrm{~nm}$ in diameter), Pellarin measured the absorption spectra of pure noble metal clusters and also bimetallic clusters like

\footnotetext{
* ISSPIC 16 - 16th International Symposium on Small Particles and Inorganic Clusters, edited by Kristiaan Temst, Margriet J. Van Bael, Ewald Janssens, H.-G. Boyen and Françoise Remacle.

a e-mail: franck.rabilloud@univ-lyon1.fr
}

silver-nickel nanoparticles [2]. The main feature of the optical response to excitation by light is an absorption band in the UV-visible range related to the surface plasmon resonance. However, in the case of silver-nickel nanoparticles a broadening and a damping of the surface plasmon resonance band were observed with increasing nickel proportion compared to the pure silver cluster.

Theoretically, ab initio optical spectra of very small clusters were first calculated in the framework of the interaction of configurations (CI) or in the linear response equation-of-motion coupled-cluster (EOM-CC) method $[14,15]$. More recently a few studies in the framework of the time-dependent density functional theory (TDDFT) were performed on small noble metal clusters and bimetallic clusters [16-23]. While such quantum calculations taking into account the electronic structure, with an explicit treatment of both $s$ - and $d$-electrons, can be used to simulate the optical absorption of small noble metal clusters or transition metal clusters (i.e. several tens of atoms), they are not available up to now for large nanoparticles. The observed spectra for large noble metal clusters were successfully interpreted by adopting the point of view that they reflect a collective excitation of valence electrons, and that Mie theory in relation to simple models can be used to describe them. Thus the interaction of light with the particle embedded in a medium is described in the framework of classical optics, assuming that the particle and the medium are continuous, homogeneous, and characterized by their dielectric function. This theory involves explicitly only the $s$-type electrons in collective excitations (called plasmon), while $d$-type electrons are only taken into account via the dielectric function [24]. It well reproduces the experimental absorption spectra for large particles (diameter of about $2-10 \mathrm{~nm}$ ) both of pure silver clusters and mixed silver-nickel clusters [2,25].

In the present work, we investigate UV-visible absorption spectra of pure silver or nickel clusters and mixed 

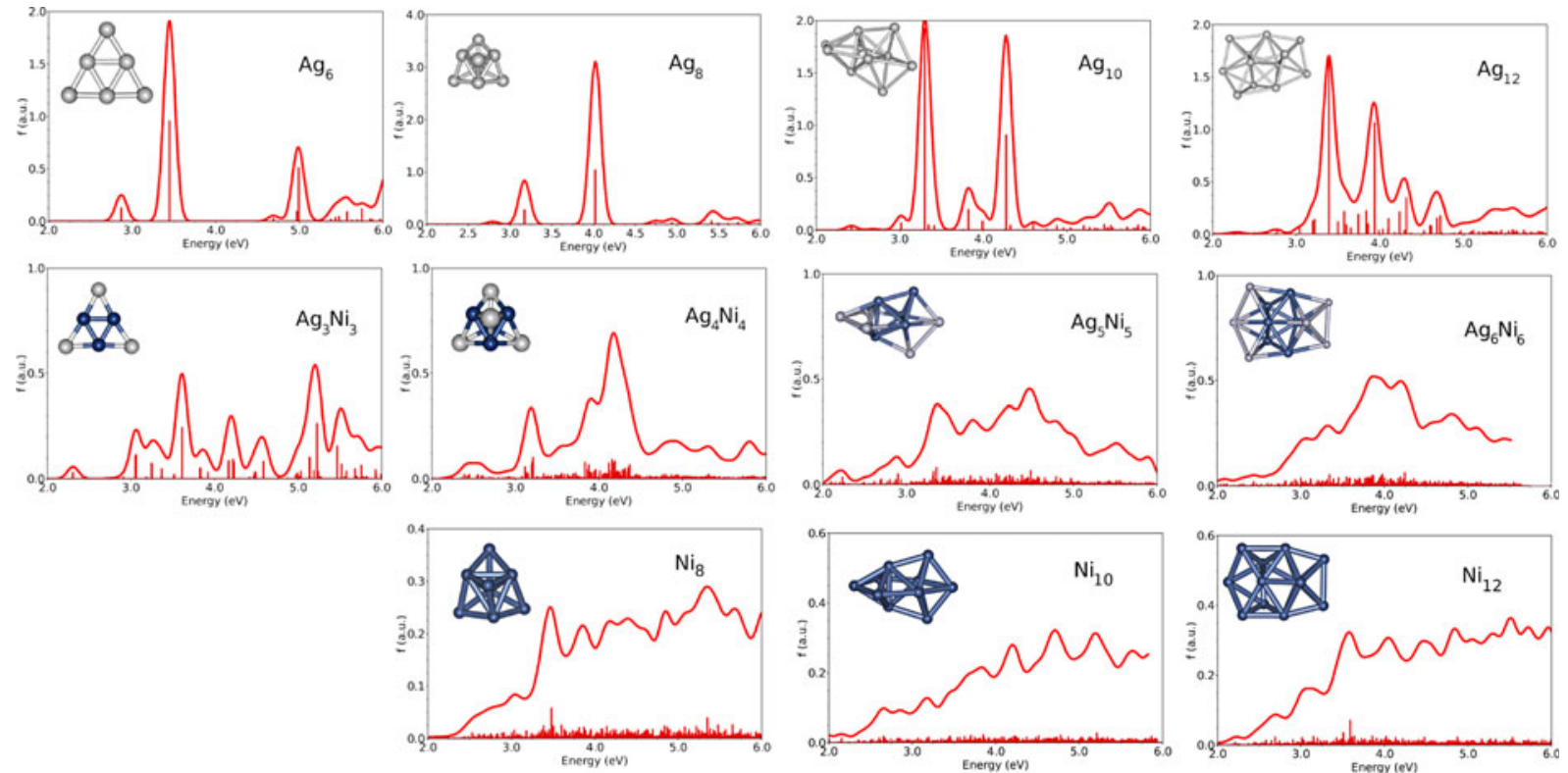

Fig. 1. Absorption spectra of $\mathrm{Ag}_{n} \mathrm{Ni}_{n}, \mathrm{Ag}_{2 n}$ and $\mathrm{Ni}_{2 n}$ clusters $(n=3-6)$.

silver-nickel clusters from TDDFT calculations. In contrast with previous studies on similar systems in which TDDFT calculations were performed with standard GGA (generalized gradient approximation) or LDA (local density approximation) functionals $[4,7,16,18,22]$, the present TDDFT are performed using a long-range corrected density functional in order to give a more suitable description of charge-transfer excitations.

\section{Computational details}

Calculations were performed in the framework of density-functional theory (DFT) implemented in the GAUSSIAN09 package [26]. All atoms were described through relativistic or quasi-relativistic core potentials, so that only 19 and 18 valence electrons were treated explicitly for $\mathrm{Ag}$ and $\mathrm{Ni}$ respectively [27]. The basis set was $8 s 7 p 6 d 1 f$ contracted into $6 s 5 p 3 d 1 f$ on both silver and nickel atoms. The cluster geometries, taken from references $[4,19,28]$, were optimized with the hybrid functional B3LYP which involves Becke's three-parameter exchange functional $[29,30]$. The TDDFT calculation of the optical properties (excitation energies, oscillator strengths and transition dipole moments) has been carried out using the functional CAM-B3LYP which combines the hybrid B3LYP functional at short range with an increasing amount of exact Hartree-Fock exchange at long-range [31]. CAM-B3LYP is expected to give a much better description of charge-transfer excitations than standard functionals does thanks to the modulation of the exact exchange [32]. The spectra presented in the figures below give the oscillator strength as a function of the excitation energy, together with a curve obtained by a Gaussian broadening (with a full width of half-height of $0.08 \mathrm{eV}$ ). Pre- and post-processing operations were performed by using the graphical interface Gabedit [33].

\section{Results and discussion}

\subsection{Absorption spectra of silver clusters}

Absorption spectra of small silver clusters $\operatorname{Ag}_{n}$ with $n=6$, 8, 10 and 12, are shown in Figure 1. They are characterized by a strong optical response in the $3-5 \mathrm{eV}$ range with one or two dominant peaks. For $\mathrm{Ag}_{6}$, the present calculation gives a main strong peak at $3.45 \mathrm{eV}$ and a less intense one at $2.87 \mathrm{eV}$. Then a strong peak appears at $4.99 \mathrm{eV}$ followed by less intense structures beyond $5 \mathrm{eV}$. The experimental spectrum measured on clusters isolated in a rare-gas matrix shows mainly one intense and narrow transition at $3.45 \mathrm{eV}$ with a shoulder at $3.65 \mathrm{eV}$ [12]. The experimental transition at $3.45 \mathrm{eV}$ is very well reproduced in the present calculation, but the shoulder is not seen in the calculation. To explain the shoulder, one can argue that the calculated strong transition at $3.45 \mathrm{eV}$ is doubly degenerated and this degeneracy might be lifted up when this system is embedded inside a matrix. One can note also that calculation shows symmetry forbidden transitions at $3.55 \mathrm{eV}$ that could possibly be observed when the cluster is embedded due to the interaction with the rare-gas atoms. The smaller intensity calculated peaks at $2.87 \mathrm{eV}$ and beyond $5 \mathrm{eV}$ fit well the experimental structures. For $\mathrm{Ag}_{8}$, two strong triply degenerated transitions are calculated at 3.18 and $4.02 \mathrm{eV}$. The calculation reproduces very the experimental spectrum in which a main peak at $4.00 \mathrm{eV}$ is observed, as well as less intense transitions at 3.12 and $3.20 \mathrm{eV}$ [12]. Beside the smaller structures observed in experiment around 2.55 and $5.40 \mathrm{eV}$ are also reproduced in our calculation. However, the extra narrow peak at $3.65 \mathrm{eV}$ observed in experiment can not be seen in our calculated spectrum. It could be associated to another isomer as suggested in references [4,12]. Indeed, the calculated spectrum of a $D_{2 d}$ structure lying $0.09 \mathrm{eV}$ above the present $T_{d}$ structure shows a peak at 

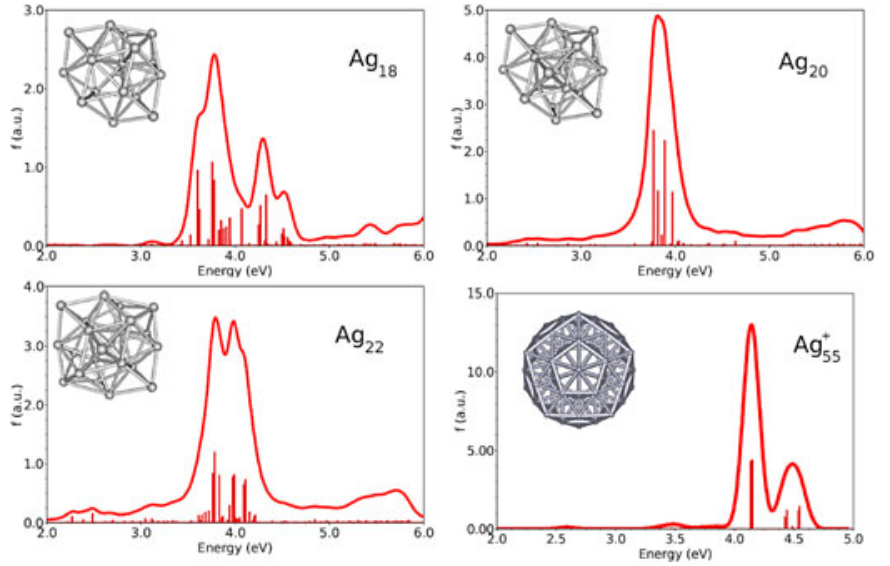

Fig. 2. Absorption spectra of $\mathrm{Ag}_{18}, \mathrm{Ag}_{20}, \mathrm{Ag}_{22}$ and $\mathrm{Ag}_{55}^{+}$ clusters.

$3.65 \mathrm{eV}$ [12]. For $\mathrm{Ag}_{10}$, the calculated spectrum shows two main peaks at 3.30 and $4.27 \mathrm{eV}$, the latter being doubly degenerated. The peak at $3.30 \mathrm{eV}$ has small shoulders at both higher energy (transitions at 3.34 and $3.41 \mathrm{eV}$ ) and lower energy (transitions at $3.02 \mathrm{eV}$ ). A doubly degenerated transition at $3.82 \mathrm{eV}$ with a shoulder at $3.99 \mathrm{eV}$ can also be seen in the spectrum. In experiment, the formation of $\mathrm{Ag}_{10}$ cluster is unfavorable and only one spectrum can be found in the litterature [4]. Although the signal to noise ratio of the experimental spectrum is low, it shows three distinct narrow lines at 3.79, 3.98 and $4.15 \mathrm{eV}$, which could correspond to the present three main peaks. However, the experimental spectrum should be confirmed because its similarities with the spectrum of $\mathrm{Ag}_{9}$ suggest a fragmentation of $\mathrm{Ag}_{10}$ into $\mathrm{Ag}_{9}+\mathrm{Ag}$ atoms after the mass selection, so that the spectrum could be associated to $\mathrm{Ag}_{9}$ cluster [4]. The calculated spectrum of $\mathrm{Ag}_{12}$ shows four main peaks centered at $3.39,3.94,4.32$ and $4.68 \mathrm{eV}$, surrounded by less intense transitions. This is in very good agreement with the experimental spectrum which presents strong lines at $3.42,3.91$, and $4.38 \mathrm{eV}$ respectively [4].

For larger clusters, the absorption spectra are characterized by the emergence of a dominant and relatively broad peak around $4.0 \mathrm{eV}$, with very strong oscillator strengths, and eventually accompanied by one or two peaks at higher energies but smaller intensities. Figure 2 gives spectra of $\mathrm{Ag}_{18}, \mathrm{Ag}_{20}, \mathrm{Ag}_{22}$, and $\mathrm{Ag}_{55}^{+}$clusters. The calculated spectrum of $\mathrm{Ag}_{18}$ shows several peaks well scattered on the $3.5-4.5 \mathrm{eV}$ range, with main peaks at 3.61 , $3.76,4.07,4.27,4.33$ and $4.50 \mathrm{eV}$, and leading to a broad band whose the exact shape depends on the Gaussian broadening. However, it reproduces well the experimental spectrum which presents a relatively broad band between 3.5 and $4.5 \mathrm{eV}$ with two maxima at 3.62 and $4.04 \mathrm{eV}$ [10]. For $\mathrm{Ag}_{20}$, the calculated spectrum gives a band centered at $3.85 \mathrm{eV}$ and made of four strong lines at $3.77,3.81,3.89$, and $3.97 \mathrm{eV}$. It is in good agreement with the experimental band centered at $3.70 \mathrm{eV}[10]$. The absorption spectrum of $\mathrm{Ag}_{22}$ shows a broad band on the $3.6-4.2 \mathrm{eV}$ range, with main peaks at $3.78,3.83,3.97$ and $4.11 \mathrm{eV}$. No experimental data is available. Finally, we give in Figure 2 the spectrum of $\mathrm{Ag}_{55}^{+}$. To reduce the calculations time, the $\mathrm{I}_{h}$-symmetry structure was optimised using the BP86 functional $[34,35]$ and the relativistic effective core potential LanL2DZ and related basis sets [36]. Then the absorption spectrum was calculated at CAM-B3LYP/LanL2DZ level. Two strong bands can be seen in Figure 2. The first one is composed of three strong quasi-degenerated transitions at $4.14 \mathrm{eV}$, and the second one results from transitions at 4.42, 4.44, 4.54 and $4.55 \mathrm{eV}$. Recently, Weissker [22] computed the spectrum of $\mathrm{Ag}_{55}$ at Real-time TDDFT level using a GGA functional. They found a main band at about $3.7 \mathrm{eV}$, and less intense one at about $3.4 \mathrm{eV}$. The use of a long-range corrected density functional like CAM-B3LYP in the present work leads to a blueshift of the main peak of about $0.44 \mathrm{eV}$. Calculations by Aikens et al. [37] at TDDFT/BP86 level on tetrahedral $\mathrm{Ag}_{56}^{+}$cluster show a band centered at about $3.1 \mathrm{eV}$. To my knowledge, there is no experimental spectrum on neutral or cationic $\mathrm{Ag}_{55}^{(+)}$cluster, but experiments on clusters of similar sizes $(n=39-60)$ suggest that the spectrum of $\mathrm{Ag}_{55}^{+}$could present a main band on the $3.5-4.0 \mathrm{eV}$ range $[9,10,13]$.

To my knownledge, the present work is the first one which investigates silver clusters with the use of a density functional involving a long-range correction, the latter being expected to give a much more suitable description of charge-transfer excitations. The present CAM-B3LYP spectra provide significant improvement with respect to our previous work using the GGA-type BP86 functional and the LanL2Dz basis set [4], and compare well with experimental spectra. In particular, significant agreements are obtained for the following clusters: $\mathrm{Ag}_{6}$ for which the main CAM-B3LYP transition calculated at $3.45 \mathrm{eV}$ is exactly the experimental value, $\mathrm{Ag}_{10}$ for which the spectra is quite different than that calculated at BP86 level, and $\mathrm{Ag}_{12}$ for which the main calculated transitions are blueshifted by about $0.5 \mathrm{eV}$ with respect to BP86 ones and reproduce well the experimental spectrum. For larger clusters $\mathrm{Ag}_{n}$ with $n=18,20,22$, the CAM-B3LYP bands are blueshifted by about $0.2-0.4 \mathrm{eV}$ with respect to those calculated at BP86 level.

The spectra of $\operatorname{Ag}_{n}$ clusters evolve with increasing $n$ from molecular-like, characterized by several wellseparated peaks, to plasmon-like charaterized by a single and relatively broad band in the UV-visible domain (see Figs. 1 and 2). For intermediate sizes $(n=10-18)$, many transitions are well scattered on the $2-6 \mathrm{eV}$ range, and then for $n \geq 20$ the allowed transitions (no zero oscillator strenght) are brought together on a relatively short range of energy, so that the absorption spectra become more regular with only one main intense peak without dispersion of the oscillator strengths over other states (in agreement with the fact that the structure becomes more spherical). For $n \geq 20$, the spectra shape reminds the surface plasmon, well-known feature of metallic particles, and usually described as a collective excitations of $s$-type electrons. To characterize the excitations in our TDDFT calculations, we show in Figure 3 a plot of the electron density difference between the excited and the ground states for one of the main peaks of the spectrum of $\mathrm{Ag}_{20}$ (we have checked that 

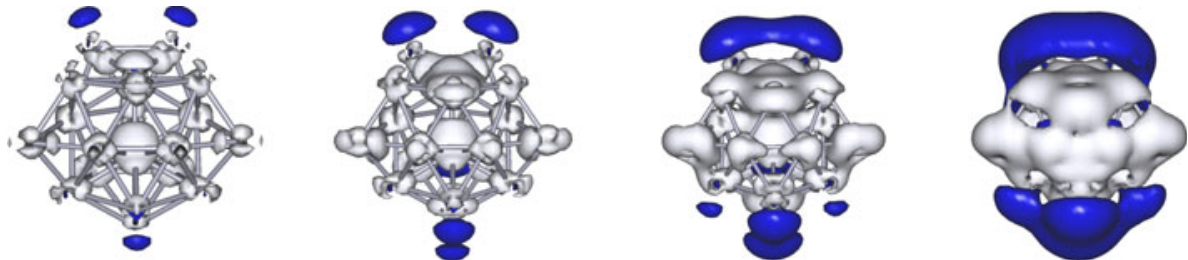

Fig. 3. Isosurface of the electron density difference between the excited and ground states for the peak at $3.89 \mathrm{eV}$ of $\mathrm{Ag}_{20}$ clusters. The isovalues are 0.0004, 0.0003, 0.0002, and 0.0001 a.u. respectively. Light regions correspond to the depletion of the electron density during the transition while the dark (blue online) regions correspond to the accumulation of electrons.
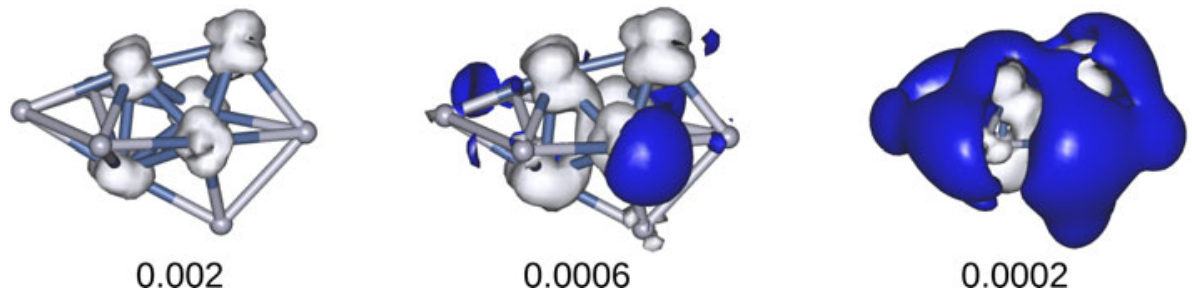

Fig. 4. Isosurface of the electron density difference between the excited and ground states for the peak at $3.35 \mathrm{eV}^{\mathrm{a}} \mathrm{Ag}_{5} \mathrm{Ni}_{5}$ clusters. The isovalues are given in a.u. Light regions correspond to the depletion of the electron density during the transition while the dark (blue online) regions correspond to the accumulation of electrons.

the conclusions found for its peak are generalized for the others). Light colored regions correspond to depletion of the electron density during the transition, while dark (blue online) regions correspond to an increase of the electron density. It appears that the transition is due to the excitations from inner orbitals, with a shape associated to $d$ and $s$ contributions, to outer region with an $s+p$ character. The accumulation of the electrons is found to be done rather outside the cluster. Thus, quantum chemistry calculations give a new description of absorption spectra of metallic nanoparticles in which the role of $d$ electrons is important. It contrasts with the commonly used semiclassical description based on the Mie theory to explain spectra of larger nanoparticles, in which the transitions are described by a collective excitation of $s$ valence electrons while the effect of $d$ electrons are taken into account through a phenomenological dielectric function $[24,25]$. In our quantum calculation, the $d$-type electrons seem more active, and the interband transitions $d \rightarrow s p$ appears more important.

\subsection{Absorption spectra of silver-nickel clusters}

The structure of bimetallic $\mathrm{Ag}_{n} \mathrm{Ni}_{n}$ clusters has been investigated both in experiment [2] and computations $[6,7,19]$. It is governed essentially by the formation of a Ni-core surrounded by silver atoms. In a recent study of the optical properties [2], it was shown that the absorption spectra of large Ag-Ni bimetallic (about 2-5 nm of size) clusters are intermediate between those of pure silver and pure nickel clusters, with a surface plasmon resonance strongly broadened in comparison to pure silver particles. Although TDDFT calculations are not possible on such large systems, we can get useful information by studying smaller clusters, for which accurate calculations of the electronic structure can be done. Figure 1 gives the absorption spectra of $\mathrm{Ag}_{n} \mathrm{Ni}_{n} n=3-6$, together with those of $\mathrm{Ni}_{2 n}$ and $\mathrm{Ag}_{2 n}$. The geometrical structures are fixed to those of $\mathrm{Ag}_{2 n}$, i.e., the structures of $\mathrm{Ag}_{n} \mathrm{Ni}_{n}$ and $\mathrm{Ni}_{2 n}$ clusters are obtained by local optimizations starting from the structure of the lowest-energy isomer of $\mathrm{Ag}_{2 n}$ after substitutions of some silver atoms by the nickel ones. Spectra given in Figure 1 show clearly that the presence of nickel atoms leads to an high increased spectral density compared to the case of pure silver clusters. The spectrum of $\mathrm{Ag}_{3} \mathrm{Ni}_{3}$ is composed of several transitions well separated and well scattered on the $3-6 \mathrm{eV}$ range. In comparison with the spectrum of $\mathrm{Ag}_{6}$, the main transitions originally at $2.87,3.45$, and $4.99 \mathrm{eV}$, are blueshited to $3.06,3.61$ and $5.23 \mathrm{eV}$. The spectrum of $\mathrm{Ni}_{6}$ was not calculated because the triangular structure considered here for this size is not a local minimum. For $\mathrm{Ag}_{4} \mathrm{Ni}_{4}$, the high density of transitions leads to main bands centered at 3.18 and $4.17 \mathrm{eV}$ with some shoulders at 3.55 and $3.89 \mathrm{eV}$. The spectrum is intermediate between the spectrum of $\mathrm{Ag}_{8}$ which presents two main peaks at 3.18 and $4.02 \mathrm{eV}$, and that of $\mathrm{Ni}_{8}$ which presents no dominant peak (except a relatively strong transition at $3.45 \mathrm{eV}$ ). For $\mathrm{Ag}_{5} \mathrm{Ni}_{5}$ and $\mathrm{Ag}_{6} \mathrm{Ni}_{6}$, the spectral density become very high resulting into spectra without dominant peak and with a shape similar to those of the spectra of $\mathrm{Ni}_{2 n}$ clusters. The great similarity of the spectra compared to those of $\mathrm{Ni}_{2 n}$ suggests that the $d$-type electrons of $\mathrm{Ni}$ should play an important role in the excitations. Figure 4 shows the electron density difference between the excited and ground states for a representative peak in the case of $\mathrm{Ag}_{5} \mathrm{Ni}_{5}$. Since the latter is part of a continuum, we have checked that the conclusions found for its peak are generalized for the others. Transitions are clearly associted to $d$ electrons of nickel atoms since the excitations are from $d$-orbitals of nickel atoms with a very weak contribution from silver atoms to wide areas involving all atoms. The present analysis of the electronic excitations shows the crucial role of the $d$ electrons 
of nickel atoms in the optical transitions in small silvernickel nanoparticles.

The present results show that spectra of $\mathrm{Ag}_{n} \mathrm{Ni}_{n}$ clusters are broadened and damped as compared to those of $\mathrm{Ag}_{2 n}$, and are in good agreement with the experimental data obtained for the large $\mathrm{AgNi}$ core/shell clusters of $2-5 \mathrm{~nm}$ of size for which a broadening and damping of the surface plasmon resonance band with increasing nickel proportion were observed compared with the pure silver [2].

\section{Conclusion}

We have presented the absorption spectra of pure silver, nickel and mixed silver-nickel clusters from TDDFT calculations. Although the spectra observed experimentally are sometime likely to be due to the contributions of a mixture of isomers, we have investigated only the lowestenergy isomer for each nuclearity. For large clusters, only the icosahedron $\mathrm{Ag}_{55}$ have been considered since this isomer of high-symmetry is expected to be likely formed in experiments. Our calculations are shown to well reproduce the experimental spectra usually interpreted in the framework of classical optics in term of collective excitation of $s$-type electrons (plasmon). However, in the case of mixed $\mathrm{Ag}_{n} \mathrm{Ni}_{n}$ clusters, transitions are found to be associated to excitations of $d$-type electrons of nickel atoms.

The author thanks the Pôle Scientifique de Modélisation Numérique (PSMN) at Lyon, France, for generous allocation of computational time.

\section{References}

1. M.C. Daniel, D. Astruc, Chem. Rev. 104, 293 (2004)

2. M. Gaudry, J. Lermé, E. Cottancin, M. Pellarin, J.L. Vialle, M. Broyer, B. Prével, M. Treilleux, P. Mélinon, Phys. Rev. B 64, 085407 (2001)

3. O.M. Bakr, V. Amendola, C.M. Aikens, W. Wenseleers, R. Li, L. Dal Negro, G.C. Schatz, F. Stellacci, Angew. Chem. Int. Ed. 48, 5921 (2009)

4. M. Harb, F. Rabilloud, D. Simon, A. Rydlo, S. Lecoultre, F. Conus, V. Rodrigues, C. Félix, J. Chem. Phys. 129, 194108 (2008)

5. C.M. Ritchie, K.R. Johnsen, J.R. Kiser, Y. Antoku, R.M. Dickson, J.T. Petty, J. Phys. Chem. C 111, 175 (2007)

6. G. Rossi, A. Rapallo, C. Mottet, A. Fortunelli, F. Baletto, R. Ferrando, Phys. Rev. Lett. 93, 105503 (2004)

7. M. Harb, F. Rabilloud, D. Simon, Phys. Chem. Chem. Phys. 12, 4246 (2010)
8. J. Tiggesbaumker, L. Koller, H.O. Lutz, K.H. MeiwesBroer, Chem. Phys. Lett. 190, 42 (1992)

9. J. Tiggesbaumker, L. Koller, H.O. Lutz, K.H. MeiwesBroer, A. Liebsch, Phys. Rev. A 48, R1749 (1993)

10. S. Fedrigo, W. Harbich, J. Buttet, Phys. Rev. B 47, 10706 (1993)

11. S. Fedrigo, W. Harbich, J. Belyaev, J. Buttet, Chem. Phys. Lett. 211, 166 (1993)

12. S. Lecoultre, A. Rydlo, C. Félix, J. Buttet, S. Gilb, W. Harbich, J. Chem. Phys. 134, 074302 (2011)

13. E. Loginov, L.F. Gomez, N. Chiang, A. Halder, N. Guggemos, V.V. Kresin, A.F. Vilesov, Phys. Rev. Lett. 106, 233401 (2011)

14. V. Bonacic-Koutecky, J. Pittner, M. Boiron, P. Fantucci, J. Chem. Phys. 110, 3876 (1999)

15. V. Bonacic-Koutecky, V. Veyret, R. Mitric, J. Chem. Phys. 115, 10450 (2001)

16. M. Harb, F. Rabilloud, D. Simon, Chem. Phys. Lett. 449, 38 (2007)

17. M. Harb, F. Rabilloud, D. Simon, Chem. Phys. Lett. 476, $186(2009)$

18. K. Baishya, J.C. Idrobo, S. Ogut, M. Yang, K. Jackson, J. Jellinek, Phys. Rev. B 78, 075439 (2008)

19. M. Harb, F. Rabilloud, D. Simon, J. Chem. Phys. 131, $174302(2009)$

20. N. Durante, A. Fortunelli, M. Broyer, M. Stener, J. Phys. Chem. C 115, 6277 (2011)

21. G. Barcaro, M. Broyer, N. Durante, A. Fortunelli, M. Stener, J. Phys. Chem. C 115, 24085 (2011)

22. H.C. Weissker, C. Mottet, Phys. Rev. B 84, 165443 (2011)

23. M. Harb, F. Rabilloud, D. Simon, J. Phys. B: At. Mol. Opt. Phys. 44, 035101 (2011)

24. J. Lermé, Eur. Phys. J. D 10, 265 (2000)

25. E. Cottancin, G. Celep, J. Lermé, M. Pellarin, J.R. Huntzinger, J.L. Vialle, M. Broyer, Theor. Chem. Acc. 116, 514 (2006)

26. M.J. Frisch et al., Gaussian 09, Revision A.1 (Gaussian Inc., Wallingford, CT, 2009)

27. D. Andrae, U. Haussermann, M. Dolg, H. Stoll, H. Preuss, Theor. Chim. Acta 77, 123 (1990)

28. M. Harb, F. Rabilloud, D. Simon, J. Phys. Chem. A 111, 7726 (2007)

29. A.D. Becke, J. Chem. Phys. 98, 5648 (1993)

30. C. Lee, W. Yang, R.G. Parr, Phys. Rev. B 37, 785 (1988)

31. T. Yanai, D.P. Tew, N.C. Handy, Chem. Phys. Lett. 393, $51(2004)$

32. F. Rabilloud, Recent Res. Devel. Chem. Phys. 6, 67 (2012)

33. A.R. Allouche, J. Comput. Chem. 32, 174 (2011)

34. A.D. Becke, Phys. Rev. A 38, 3098 (1988)

35. J.P. Perdew, Phys. Rev. B 33, 8822 (1986)

36. P.J. Hay, W.R. Wadt, J. Chem. Phys. 82, 299 (1985)

37. C.M. Aikens, S. Li, G.C. Schatz, J. Phys. Chem. C 112, $11272(2008)$ 